\title{
What You Create Is What You Learn
}

\author{
Monika Sonta, \\ Kozminski University, Warsaw, Poland
}

Stawomir Magala,

\author{
Erasmus University Rotterdam, the Netherlands
}

\begin{abstract}
The objective of this paper is to check whether what you see is what you get. In other words, to present an application of a 'Vision Board' (VB) technique in the academic classroom as an innovative and creativity-boosting practice.

The authors start with the definition of Vision Boards born out of academic wedlock, primarily in art. It is the avant-garde art of the past century that shaped our visual thinking. Artistic experiments gave us collage (from Braque to Schwitters and from Hamilton to Beuys). Artists expressed the fragmentary and relative nature of our perception of reality. Cunning passages led from art shows to university classrooms: this is how a modular ready-to-use creative workshop scenario designed for 60 minutes had emerged. Art shows that the public brings the relativity of aesthetic evaluation with "beauty in the eye of the beholder." Does the student audience echo this claim to observer's, receiver's, reader's, viewer's, and listener's relative and subjective response? In search of an answer, we discuss the drives of student engagement, demonstrated by student decisions to contribute to a collective VB activity with personal Artistic expression, input Creation, process Control, Context defining, Emergence monitoring, and Emotions gauging.

Moreover, the authors share their practical experiences from student workshops and the creation of 25 Vision Boards and the potential pains and gains of the application of $\mathrm{VB}$ in the classroom. The attention is drawn to a) linking playful experiences to serious topics and theoretical concepts and b) leveraging creative discoveries by upgrading output required by course syllabi.
\end{abstract}

Keywords: Experiential Learning; Visual Representation; Social Learning; Manual Thinking; Playful Learning; Projective Techniques

Received: 23 July 2020

ISSN 2056-757X

Revised: 23 Aug 2020

Accepted: 1 Sept 2020

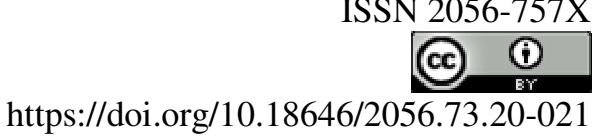




\section{Introduction}

The objective of this paper is to present an application of a 'Vision Board' technique in the academic classroom and share experience with Vision Boards as an innovative and creativity-boosting practice in higher education teaching. The focal module of this article is a ready-to-apply workshop scenario.

We will focus on the reasons that encourage people to experiment with this method of work and expose its potential risks. In the background, we will discuss the drivers of student engagement during creative workshops. The most vivid discovery of the authors is the bipolarity of students' opinions about 'Visual Boards' mini-workshops, which raises questions about ambiguities of knowledge transfer techniques in a rapidly expanding and egalitarian higher education.

The Vision Board technique was tested during nine courses in the field of marketing, innovation, and cross-cultural management during the first (opening) sessions of each course by Monika Sońta. From October 2019 to March 2020, twenty-five vision boards have been created by students of master's degree programme in Management at Kozminski University in Warsaw, Poland.

\section{WHAT: Vision Board Technique Based on the Collage Method}

A Vision Board is a one-page collage, a composition consisting of press clippings with illustrated magazine images, random pictures, personal drawings, and assembled texts. Usually, the collage created as a vision board resembles a mixture of ready-to-use visual elements, combined in a random way.

Vision Boards may be treated as:

1) Concept Posters when the aim is to explain a concept by illustrating its manifestations;

or, as

2) Mood Boards that are products of free associations, whose authors focused on the visual representation of their emotional states.

As a teaching method, Vision Boards are to express ideas or illustrate responses to given answers through a collection of selected images with elements of individually authored drawings and texts randomly selected and combined. In the process of producing the assemblage, images feed creators' imaginations - as one of the first feedbacks in the whole process - and help to find further visual analogies to abstract concepts and formal definitions.

A Vision Board is a projective technique that helps students in framing discussions around topics that may be presented very generally, in an abstract form, or may be introduced for the very first time. Students have an opportunity to explore meanings vividly exposed in front of them, and they can sort out their interpretations by arranging successive associations and images. Thus, collages play the role of visual

International Journal of Management and Applied Research, 2020, Vol. 7, No. 3 
artefacts. Workshop participants not only explore visual associations and build personalised stories, but they also reflect on and interpret a question or concept in a more abstract and less instrumental and linear way. The key terms are not presented and given by the tutor in advance, but they are explored and elaborated in the process of group conversation.

The collage method itself can be explained as a collection of frames (McMullin, 2016) or a design montage (Skjulstad, 2007) which domesticates abstractions and dissolves them in a stream of visual associations and storytelling improvisations. Early researchers indicate the following features of the collage method in teaching:

- elements;

- pulsations;

- fragments;

- flashes that act for participants as visual stimuli.

According to Tarnay (2012) fragmentariness is a key element of the collage-creating experience: "[T]he fragmentariness of the image may be taken to be the result of the artist's creative gesture by means of which he or she cuts out certain "snapshots" from the irreducible continuity of the outward world in order to tell a story about it" (Tarnay, 2012, p. 395).

A Vision Board is never final, the designed time pressure creates the feeling of a work that should be delivered even if incomplete. In most cases, the selected recombined photos come from a previous context. These photographs were transformed according to emergent interpretations. And yet, students are expected to present a complete story that explains the shape of Vision Board at which they arrive.

Furthermore, taking into account the image-centred consumption trend - suffice to consider the density of social media visuals - the students are tacitly, implicitly familiar with the 'collage' form of expression as they are familiar with formats used in various social media platforms such as Instagram (the Layout from Instagram app), Canva, Adobe Spark, or Google photo streams.

Illustration 1: Visual Boards created by the group of master's degree students, Cross-Cultural Management Course, Spring Semester 2020

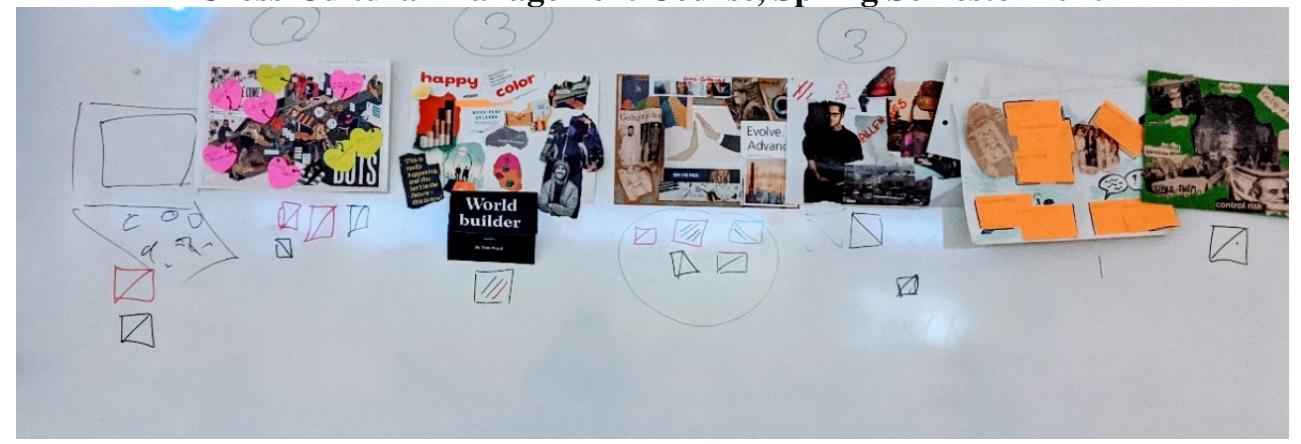

"Challenges of Cross-Cultural Management" by Monika Sońta, licensed under CC BY 2.0.

International Journal of Management and Applied Research, 2020, Vol. 7, No. 3 


\section{WHY: Is the 'Visual Projective Techniques' Method Worth Trying?}

Innovation usually leads to experiments. Experiments bring risks. How could an academic teacher know if the use of the 'Visual Board technique' in academic courses is not too risky; in other words, whether designing creative experiences is worth the effort and whether cognitive gains of students remains in line with learning process framework? With such an abstract exercise based on co-creation and visual representation of concepts, the learning output depends more on unpredictable responses, spontaneous reflexive process and unplanned emotions evoked during the exercise than on a measurable increase in the theoretical knowledge of students.

This method focuses more on stimulating conversations - these conversations ideally turn into creative dialogues envisioned by all masters of pedagogic thought - and encourages students to self-reflect rather than passively listen to lectures understood as explaining a theoretical background to an ignorant audience. As interpretations emerge, the appearing reflections take students closer to the situational discoveries that redirect students' attention into - sometimes, frequently - unexpected plans and directions (McGrath, MacMillan, 2014). Still, expectations of students are directed, guided, and coached towards cognitive ventures. Students are encouraged to equip themselves with intellectual tools, with the promise of their applicability in the business world.

The framework of Vision Boards also impacts classroom power relations. The technique counters and exceeds the traditional common understanding of the lecturer's role. One is forced to abandon the traditional view of the relationship between students and teachers. It does not hold anymore that 'teachers are givers' and 'students are takers.' Student audiences are not passive recipients of knowledge transferred from above, and their role allows them to contribute and become collaborative 'co-creators' of the learning content via visualisation. Again, in the Vision Boards technique, science and scholarship imitate art by playing with visuals and creating new perspectives of expression for students:

"The process of making a creative visual artefact - as well as the artefact itself (which may be, for example, a video, drawing, collage, or imagined magazine cover) - offers a different way into an exploration of individuals' relationships with media culture” (Gauntlett, 2004, p. 2).

\subsection{What Is at Risk?}

Let us start from the student's side, that is with students' reactions and comments received after the 2019/2020 Spring semester courses, based on the open box answers from a didactic evaluation form regarding the quality of teaching: "We spent time doing art in class, which I don't see myself doing in an office in the future."

Then, we should not forget the comments overheard in the class in February 2020: "I thought we are in a master's degree programme, not in preschool."

Secondly, the clarity of theoretical content most endangered here. Relatively lowest notes were given in the category "The teacher conducted the class in a clear and

International Journal of Management and Applied Research, 2020, Vol. 7, No. 3 
understandable way" (4.55 based on 30 responses of the most recent course in International Marketing, Spring semester 2019/2020). Thus, when using projective techniques we, the academic teachers, also risk a lower scoring on 'clarity' and 'understandability.'

Finally, this may lead us to the conclusion that with the application of visual representation techniques in the classroom, we lose the precision of a well-ordered and clearly-structured theoretical knowledge transfer.

\subsection{What Are the Gains?}

Fortunately, the general positive evaluation (above 4.55 / 5.0 in all the quantified categories) for the courses that involved 'the Vision Board' method was supported with qualitative comments about the positive aspect of these courses:

"Promotion of class members' participation and the execution of works;"

"The fact that the course was very interactive in the case of drawing, I like to draw and create, so it was right for me;"

"Interesting online workshops with all those boards and canvases;"

"Case studies, examples, creative projects, very interactive;"

"The course completed with lots of creativity and fun;"

"Creativity, interaction, using a lot of tools that help to engage people;"

"Creativity, innovation, engagement, updated, dynamic."

The tone of these comments brings us to the conclusion that the application of 'Vision Board' technique was worthwhile.

In summary, we should honestly acknowledge that the application of Visions Boards may result in eliciting extreme views from students: either extremely positive or extremely negative, with little room for evaluating the course experience as 'mediocre,' 'in-between,' or 'average.' As one of the students from 2019-2020 Winter semester claimed in the evaluation form: "I am not sure if I learnt a lot, but at least I remember the discussion."

\section{HOW: Social Learning Experience with Instructional Design}

Figure 1 illustrates the workflow scheme which follows Tuckman's (1965) model of small group development: forming (briefing), storming (creating a common goal), norming (implementing agreed goal), performing (group presentation), and adjourning. The rationale of having Vision Board workshop is as follows:

- To design a positive learning experience that rewards the participation of individuals with the feeling of creation, a social learning mechanism should be introduced from the very first minute of in-class exercises.

International Journal of Management and Applied Research, 2020, Vol. 7, No. 3 
- To facilitate the dynamic flow from individual input to team cooperation, students should be divided into groups of up to five people. Group work of four or five students gives everyone an opportunity to equally contribute while freely exchanging ideas and discussing them in a limited time. Setting time pressure is also an intentional element that frames this experience to create a 'creative tension' and remove participants from their comfort zones.

Figure 1: The Vision Board workshop's suggested scheme

\section{Visual Research and viewing materials (individual)}

\section{Creating a pool of options (individual contribution)}

\section{Creating a common interpretation (group)}

\section{Final selection of visual materials (group)}

\section{Implementation of the agreed vision} (individual or group)

Comparing Vision Boards experience with other similar forms of engaging classroom activities like LEGO® SERIOUS PLAY® (Mouratoglou, 2018), we conclude that a Vision Board workshop should not take longer than 60 minutes, including 2-3 minutes time slots for presentations. The key is to keep things simple and short.

The workshop consists of three main modules:

1. Communicating instruction (explaining procedures)

2. Creating Vision Boards (taking creative rounds)

3. Debriefing (linking experiences to theories)

\section{Simple Instruction}

The essence of the instruction was to prepare a Vision Board around a theme of the conversation strictly linked to the subject of the lecture, for example:

International Journal of Management and Applied Research, 2020, Vol. 7, No. 3 
"What are key challenges for managers when they deal with cross-cultural environment?" (Cross-Cultural Management course)

"What is a secret sauce of employee engagement?" (Introduction to Human Resources Management)

"What are the trends that shape Digital Marketing?” (Digital Marketing course)

As serious play methods intend to bring a playful atmosphere, the level of engagement is crucial. Obviously, despite the playful context, we should not forget about the learning outputs of the exercise.

To ensure the sense of fairness, all groups should have access to a blank paper of the same size (A3 is preferable) and colourful markers. The instruction should be brief: "Please, visualise with a Vision Board the key challenges (or trends) in [the given subject problem area]."

The students should begin working immediately, and the teacher should ensure that all the doubts will be explained in the process. Visual representations and serious play workshops tend to be perceived as chaotic by students unfamiliar with lateral thinking patterns. The students should experience and sense the reality that is uncertain and unpredictable because when starting the exercise students do not know about the final tangible output of their work.

Creative Rounds scheme

To avoid misconceptions about expected learning outputs and associations with spontaneous child-like play, we introduce a system of taking rounds (see table 1).

Table 1: Creative Rounds Scheme

\begin{tabular}{|c|c|c|}
\hline Round & Description & Engagement Drive \\
\hline $\begin{array}{l}\text { Round } 1 \\
\text { (5 minutes) }\end{array}$ & Briefing session & Group work: forming \\
\hline $\begin{array}{l}\text { Round } 2 \\
\text { ( } 7 \text { minutes) }\end{array}$ & $\begin{array}{l}\text { Distribute materials with images } \\
\text { and ready-to-use business } \\
\text { photos (e.g. business magazines, } \\
\text { newsletters) for Vision Boards }\end{array}$ & Group work: storming \\
\hline $\begin{array}{l}\text { Round } 3 \\
\text { (3 minutes) }\end{array}$ & $\begin{array}{l}\text { Students are given time to } \\
\text { collect data via internet }\end{array}$ & Group work: norming \\
\hline $\begin{array}{l}\text { Round } 4 \\
\text { (10 minutes) }\end{array}$ & $\begin{array}{l}\text { Distribute additional materials } \\
\text { (e.g. lifestyle magazines) to } \\
\text { enable abstract associations; } \\
\text { Students are given time to put } \\
\text { all gathered information } \\
\text { together }\end{array}$ & $\begin{array}{l}\text { Working with images; } \\
\text { Hands-On Minds-On } \\
\text { Learning }\end{array}$ \\
\hline $\begin{array}{l}\text { Round } 5 \\
\text { ( } 3 \text { minutes } \\
\text { per group) }\end{array}$ & $\begin{array}{l}\text { Final round: group presentations } \\
\text { Present the idea behind the } \\
\text { Vision Board }\end{array}$ & $\begin{array}{l}\text { Group work: performing; } \\
\text { Giving visual } \\
\text { representation }\end{array}$ \\
\hline
\end{tabular}

International Journal of Management and Applied Research, 2020, Vol. 7, No. 3 


\section{Debriefing scheme: crafting narratives to overcome fragmentariness}

Debriefing happens in the moment of Vision Boards presentation in front of the class, and the Vision Boards momentarily become only a visual background to express the story related to the task.

\section{a) Crafting Narratives}

The visual representation demands mindful debriefing to make sense by finding meanings behind abstract visuals. The meaning transfer is shaped by the narrative or micro-narrative (Devine et al., 2014). The moment of presentation is vital to express the insights (create content) and not to cease abstract visual work.

The moment of adding contextual narration and presenting (explaining) the meaning behind a Vision Board is the moment of vital importance. Susan Sontag (1979) - who often wondered if every picture tells a story or needs a caption to help it tell a story emphasises the role of narratives because only through words can we discover and understand images.

\section{b) Linking Visual Pieces Together}

The importance of fragmentariness in the creative part of the workshop is indisputable. In the first three rounds students focus more on their individual contribution through brainstorming, flipping magazine pages, and suggesting photos to their groups. This emphasises individualised interpretations of the visual materials at the students' disposal and on designing a common interpretation and narrative. In other words, this approach foregrounds a micro-discourse that becomes known after the presentation and becomes the shared artefact: a visual representation of the story.

\section{WHEN: The Timing to Employ the Vision Board Technique}

The method was used to support the ability to frame the discussion of abstract topics such as trends, key challenges, or future scenarios. The introduction of key terms by the teacher may become an entry point to a conversation about the course's subject. The key notions in the introductory lecture may be used as a beginning of a snowballing sequence in the next round of the exercise.

The first lecture of the course usually seeks to sense the level of students' knowledge, frame their expectations, and conduct initial discussions that introduce the course's subject.

Illustration 2: The vision board discussing trends in International Marketing, Spring Semester 2019.

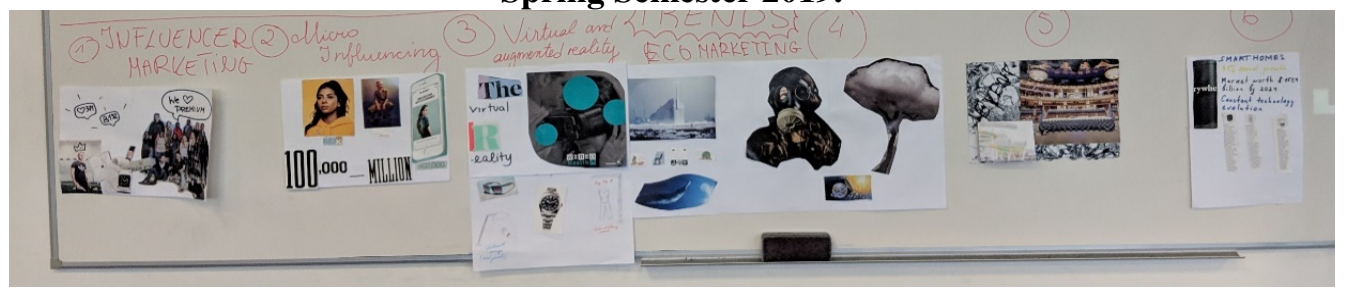

“Trends in International Marketing” by Monika Sońta is licensed under CC BY 2.0.

International Journal of Management and Applied Research, 2020, Vol. 7, No. 3 


\subsection{Reflections on the application of Vision Boards}

Vision Board as a form of expression engages participants on two levels:

- Instrumental level that stems from the application of haptic design - refer to the sense of touch, enable to create an artefact with your hands, or applying hands-on approach, mind-on method in a group of people with a purpose to activate social learning. Having tangible results further improves memorisation while writing down key terms helps remembering the concept.

- Reflexive level through Creative Discoveries because creating something leads to self-reflection and finding unexpected interpretations. The workshop participants sense the collaboration and playful atmosphere of the exercise by creating a culture of exploration (Osterwalder 2020), while still adapting to the rigid requirements of the task and referring their visual concepts to the theoretical terms explained in textbooks or by the teacher. Students have access to and use academic papers and Internet resources to 'capture' the essence of the course's subject (culture of exploitation; Osterwalder 2020).

The observable drives of engagement during a Vision Board workshop are:

\begin{tabular}{cl}
\hline Acronym & Meaning \\
\hline $\mathbf{A}$ & Artistic expression \\
$\mathbf{C}$ & Creation \\
& Control \\
& Context \\
$\mathbf{E}$ & Emergence \\
& Emotions \\
\hline
\end{tabular}

\section{The Artistic interpretation of theoretical concepts}

We may assume that Vision Boards perform poetic functions (focused on artistic characteristics more than on merits and direct interpretations) to evoke emotions, creative tensions, and emotional effects that trigger creative discoveries (Kracauer, 1975, p. 45).

Interpreting Vision Boards in categories of creative tendency: when interpreting an artwork or image, the most important critical action is the assessment of spatial relations, which is much more important than the explicit interpretation of content. Moreover, the moment of denarrativisation of the collage demands lateral thinking (lateral thinking is required to leverage visuals with a presentation related to the core question).

With the collage technique we also exclude the sense of the 'present,' the photo element used as a part of this Vision Board may be situated in a specific time to generate time-located images, especially when we use the daily business newspapers and not just images from random old magazines. However, the artistic dimension of collage and patchwork as a unitary artwork makes it a token of our imagination and

International Journal of Management and Applied Research, 2020, Vol. 7, No. 3 
timelessness. Again, the moment of presentation labels time perception as 'here and now.'

Creation: the feeling of creating something tangible, the experience or designing a closed artefact

Photographs provide us with information because they create a catalogue of interpretations (Sontag, 1979). The application of collage and ready-to-use visual elements provides a low access barrier; as it is not about drawing or sketching but more about adding ready-to-use elements, so it is a quick win and fast 'pleasure' thanks to the process of creation.

When preparing the Vision Boards, we pick images randonmly. The selection process is rapid and emergent, based on our previous experiences; however, new interpretations must be assimilated well with the existing information. Here, we should introduce the notion of apperception, which is defined as "the process by which new experience is assimilated to and transformed by the residuum of past experience of an individual to form a new whole" (Runes, 1972).

Regarding the moment of selection of photos and interpretations, the students relate to the previous individual experiences on the topic - creative discoveries are related to the previous experiences that build association with key theories and help students to memorise key definitions.

\section{Control over Chaos through enabling Choices}

Participants enjoy a spontaneous process of creation but, at a certain moment, this experience ends with taking ownership over the creative vision expressed through the collage and the formulation of a precise textual interpretation of the concept. This moment of taking control is the key experience for workshop participants. As Kracauer emphasises, one of the crucial drives of engagement in visual consumption is the experience of intentional choices when deciding on the structure of own artwork or when interpreting, for instance by editing captions (Kracauer, 1975, p. 43).

Context - the deep context of interpretation - only participants who attended the workshop can interpret Visual Boards for the rest of the audience (those who had not made it through the VB require traditional oral explanation).

The Emergence of solutions: they emerge in a 'pop up' style, stimulated by a photo or image as details may initiate a conversation.

A random photo in a magazine is a visual stimulus for the imagination and - thanks to well-designed time limitations - the decision about selecting this picture or another should be immediate.

International Journal of Management and Applied Research, 2020, Vol. 7, No. 3 
The capturing of reality in an unintended way leads to accentuating what is accidental (Kracauer p. 43), hence emphasising the role of 'punctum' (a point of attention) in details that initiate a conversation.

Explorations: Various visual forms (images, text, drawings, stamps, sticker) can be used to express a one single idea.

As Vision Boards technique focuses on randomly combining selected photos, the experience of scanning through random magazines and photos in search for an 'undefined something' is the search for a 'punctum,' something that captures our attention to such an extent that we find it worthwhile to select and interpret, a detail that enables the micro-narrative to begin. The visual exploration of the content is combined with moments of control: when participants look up the terms in a dictionary or refer to pre-readings or theories from teacher's slides to choose the best interpretation of the searched key words. Hence, all this is both an exploration and exploitation of existing sources (Osterwalder, 2020).

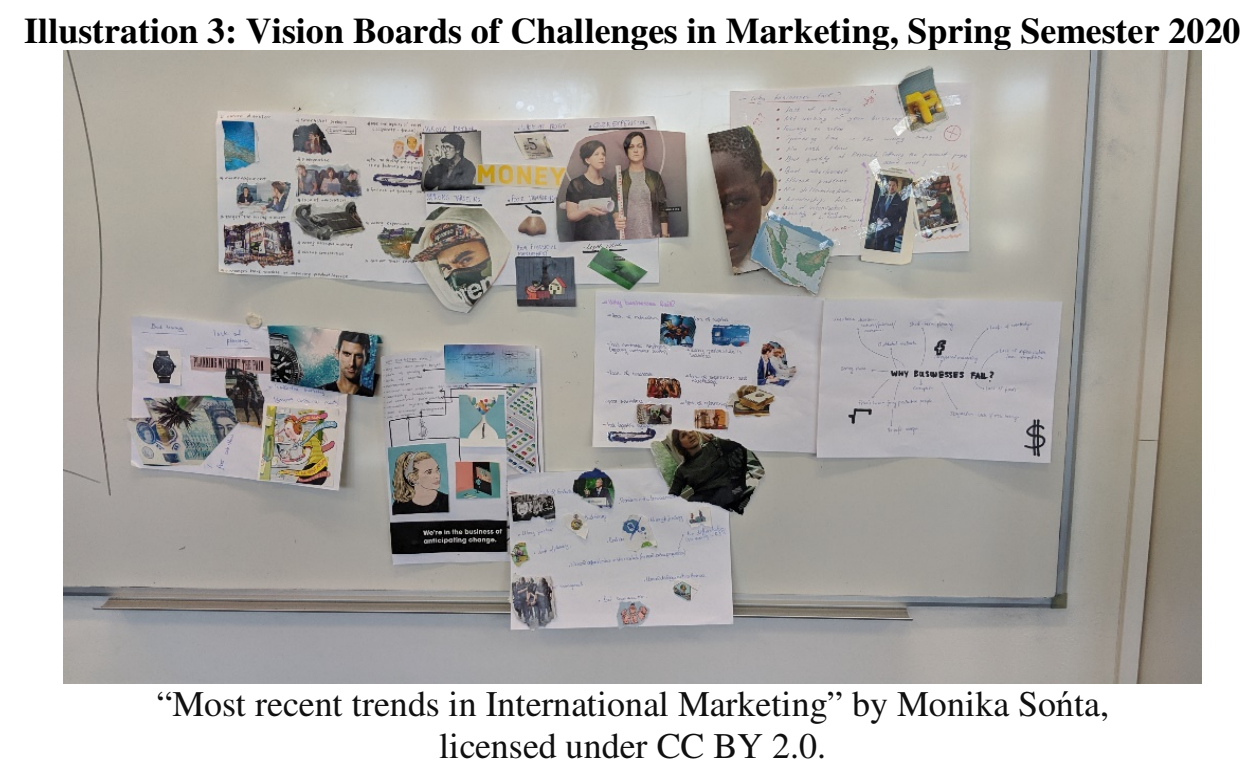

Emotions: preparing Vision Boards triggers discussions over the interpretation of the images as sharing session seeks to encourage students to express their worldview.

By introducing the Visual Board exercise, we aim to release students from 'ordinary space' (classroom) to 'emotional vibrations' through communicative interactions, in this case expressed with images (Casetti and Odin, p. 131).

Photography is the perfect tool for visual expression (Moholy-Nagy, p. 178), which Susan Sontag (1979) calls "an alibi" to serve as a source of information, presentation, meaning creation, and desire.

International Journal of Management and Applied Research, 2020, Vol. 7, No. 3 
This is particularly significant in the light of Experiential Learning Theory, according to which the experience generated during the creative session evokes emotions (Kolb, 2014) that help students memorise the content of transferred knowledge: in this case, theories and key terms.

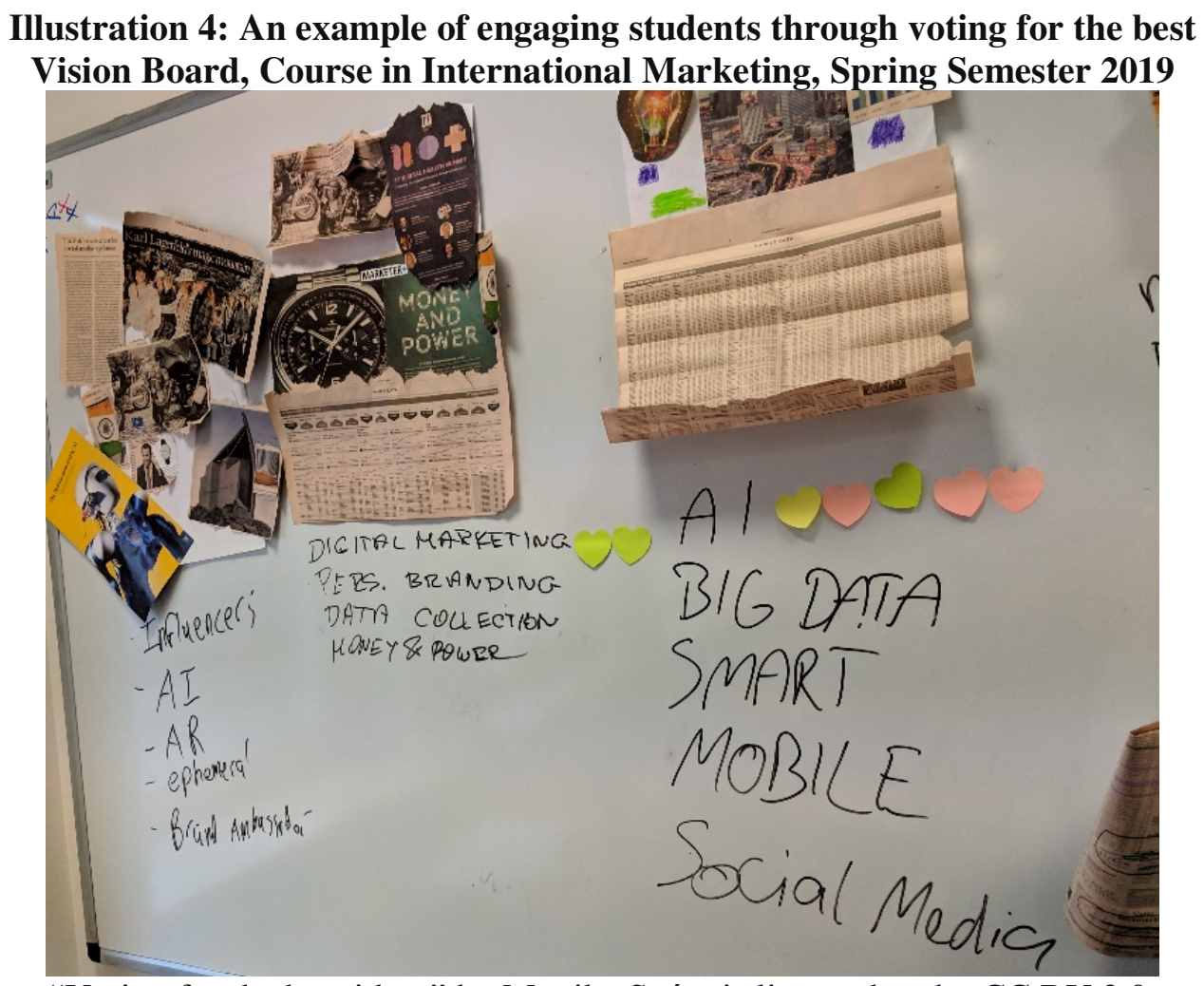

"Voting for the best ideas" by Monika Sońta is licensed under CC BY 2.0.

The final conclusion can be related to the statement that creation is equal to engagement as students are engaged through framing their 'Stream of Ideas' and conceptualizing their thoughts on an abstract in general, but specific on the merits of an academic course theme, not to mention other experiences: "...There is a lot of evidence that people like making stuff, in new and original ways, not only for its utility but because creativity carries its own rewards" (Gauntlett, 2007, p. 26).

\section{Practical Implications for Distanced Teaching}

When online class is the only option due to COVID-crisis and application of the remote learning policies, we may utilise software like linoit.com or padlet.com that enable uploading pictures and mixing them with text, or milanote.com which is a more advanced solution to create digital mood and vision boards. Students can be also asked to create their Vision Board at home and share the pictures of their artworks.

International Journal of Management and Applied Research, 2020, Vol. 7, No. 3 
In digital workshops, students can use search engines such as Google Images to seek for visual elements, so their control over content selection is higher than during a traditional workshop. The recommendation is to manoeuvre with time slots dedicated to each round so as to avoid the 'right photo search comfort zone' and enhance the experience of 'emergent' instead of deliberately selected visual content.

Finally, the application of Visual Boards technique in both digital and traditional learning environment improves the dynamics of human relationships, unleashes student creativity, and creates a playful learning climate through acts of spontaneous but structured expression.

\section{Conclusion}

The objectives of this article were to: first, to present a practical procedure of how to use Vision Boards in Higher Education at a tool-oriented level, treating Vision Boards as a visual representation technique that boosts student's creative powers; and second, to discuss the potential advantages and disadvantages of this technique, but also its engagement mechanisms.

Firstly, the 'Vision Board technique' is a relatively easily applicable method of visual representation in the academic classroom thanks to the low access barrier, as most of the visual elements are close at hand. Another advantage refers to putting them into action:

- hands-on, minds-on methods;

- social learning mechanisms; and

- playful work environment.

The main disadvantages are as follows:

- losing the clarity of explanation;

- risking the perception of 'no or low' learning output;

- the exclusion of students who are not 'creative types' and expect a more traditional and less interactive academic experience.

Moreover, the application of any new or innovative teaching technique needs to meet with the following factors:

- Expectations and Experience: students' expectations towards the learning output and experience;

- Style: the style of teacher in facilitating discussions;

- Exploration and Experiment: Organisational willingness to adopt and experiment with creative teaching methods.

Based on the feedback collected from students, we notice a clear bipolarity of opinions, as students spontaneously foreground this creative method of work as the advantage of the course. Both positive and negative evaluations are expressed with emotionally intense wording. Critical remarks and complaints require further study:

International Journal of Management and Applied Research, 2020, Vol. 7, No. 3 
quantitative research is needed to reach a less descriptive and instrumental level of analysis and ultimately to adopt a more balanced and reflexive viewpoint.

Future research directions may include the analysis of visual metaphors used in VB in the context of expressing ideas through creation of artefacts, treating Visual Boards as artworks and measuring the impact of this creative activity on the learning outputs and understanding the process of building bridges between 'the experience of creation' and obtaining more tangible results that can be used in the formal course assessment.

\section{References}

1. Casetti, F. and Odin, R. (1994), "Od paleo- do neo-telewizji. W perspektywie semiopragmatyki," Gwóźdź, A. (Ed.), Po kinie? Audiowizualność w epoce przekaźników elektronicznych, Cracow

2. Devine, J. R.; Quinn, T. and Aguilar, P. (2014), “Teaching and Transforming Through Stories: An Exploration of Macro- and Micro-Narratives as Teaching Tools," Reference Librarian, Vol. 55, No. 4, pp. 273-288. https://doi.org/10.1080/02763877.2014.939537

3. Gauntlett, D. (2004), Using new creative visual research methods to understand the place of popular media in people's lives, Porto Alegre: AMCR.

4. Gauntlett, D. (2007), Creative Explorations: New Approaches to Identities and Audiences, London: Routledge.

5. Kolb, D.A. (2014), Experiential Learning: Experience as the Source of Learning and Development. Upper Saddle River: Pearson Education

6. Kracauer S. (1975), Teoria filmu, Warszawa: WAiF.

7. McGrath, R. and MacMillan, I. (2014), "The Origins of Discovery-Driven Planning", Harvard Business Review Digital Articles. 5/29/2014, pp. 2-4.

8. McMullin, K.J. (2016), Cooperation and autonomy in language learning: An application of the collage method, Porta Linguarum, Vol. 2016, No. 25, pp. 93103

9. Moholy-Nagy, L. (1974), Vision in Motion, Chicago: Paul Theobald \& Co.

10. Mouratoglou, N. (2018), "LEGO®, Learning, and Facilitation: A Reflective Approach", International Journal of Management and Applied Research, Vol. 5, No. 4, pp. 281-289. https://doi.org/10.18646/2056.54.18-021

11. Osterwalder, A., Pigneur, Y., Smith, A., Etiemble, F. (2020), Invincible Company, Hoboken, NJ: Wiley.

12. Runes, D. D. (1972) (ed.), Dictionary of Philosophy, New Jersey: Littlefield, Adams, and Company.

13. Skjulstad, S. (2007), "Communication design and motion graphics on the Web", Journal of Media Practice, Vol. 8, No. 3, pp. 359-378. https://doi.org/10.1386/jmpr.8.3.359_1

International Journal of Management and Applied Research, 2020, Vol. 7, No. 3 
14. Sontag, S. (1979), On Photography, USA: Penguin.

15. Tarnay, L. (2012), "Realism Reconsidered: On the Aesthetic of Visual Simulation in Games", in: Pethö, A. (Eds), Film in the Post-Media Age, Newcastle upon Tyne: Cambridge Scholars Publishing, pp. 381-410.

16. Tuckman, B.W. (1965), "Developmental sequence in small groups", Psychological Bulletin, Vol. 65, No. 6, pp. 384-99.

\section{List of illustrations:}

1. Illustration 1: Visual Boards created by the group of master's degree students, Cross-Cultural Management Course, Spring Semester 2020 "Challenges of Cross-Cultural Management" by Monika Sońta is licensed under CC BY 2.0.

2. Illustration 2: The vision board discussing trends in International Marketing, Spring Semester 2019.

"Trends in International Marketing" by Monika Sońta is licensed under CC BY 2.0.

3. Illustration 3: Vision Boards of Challenges in Marketing, Spring Semester 2020

"Most recent trends in International Marketing" by Monika Sońta is licensed under CC BY 2.0.

4. Illustration 4: An example of engaging students through voting for the best Vision Board, Course in International Marketing, Spring Semester 2019 "Voting for the best ideas" by Monika Sońta is licensed under CC BY 2.0.

International Journal of Management and Applied Research, 2020, Vol. 7, No. 3 